\title{
Comparison of the Ameliorative Effects of Qing Zhi Zhi Ke Formula and Azithromycin on Mycoplasma pneumoniae Pneumonia in Mice
}

\author{
Ou-Mei Hao ${ }^{1 *}$, Xue-Feng Wang ${ }^{1}$, Zhi-Jun Yue ${ }^{1}$, Chun-Hong Nan ${ }^{1}$, Yan Yu ${ }^{1}$, \\ Tong Zhang ${ }^{2}$, Yu-Feng Liu ${ }^{3}$ and Xue Zhao ${ }^{1}$ \\ ${ }^{1}$ Affiliated Hospital to Liaoning University Traditional Chinese Medicine, Shenyang, \\ China, 110032. \\ ${ }^{2}$ Liaoning University Traditional Chinese Medicine, Shenyang, China, 110032. \\ ${ }^{3}$ The Fourth Hospital to Liaoning University Traditional Chinese Medicine, Shenyang, \\ China, 110101
}

\begin{abstract}
A B S T R A C T
The aim of this study was to assess changes in the expression levels of relevant factors associated with inflammation after Mycoplasma pneumoniae pneumonia (MPP) infection and compare the therapeutic effects of Qing Zhi Zhi Ke formula (QZZKF), QZZKF combined with azithromycin (AZM) and AZM on experimental mice. Fifty female BALB/c mice were randomly divided into five groups: control, model, AZM $(0.01 \mathrm{~g} / \mathrm{kg} / \mathrm{day})$, QZZKF $(10.16 \mathrm{~g} / \mathrm{kg} / \mathrm{day})$, AZM $(0.01 \mathrm{~g} / \mathrm{kg} / \mathrm{day})$ combined with QZZKF $(10.16$ $\mathrm{g} / \mathrm{kg} /$ day). QZZKF and AZM were administered by oral gavage every day for five days.Pathological changes in lung tissue were determined by hematoxylin and eosin. The levels of cytokines in lung tissues were assessed by Immunohistochemistry staining and Quantitative real-time (qRT)-PCR assays were performed to explore the effects of QZZKF on the expression of surfactant protein A (SP-A), B7 homolog 3 protein (B7-H3), interleukin (IL)-12 and IL-13. The expression levels of B7-H3 and IL-13 were upregulated after MPP infection in the mouse model $(\mathrm{P}<0.05)$, while the expressions of SP-A and IL-12 were significantly decreased $(\mathrm{P}<0.05)$. After five days of therapy, the protein and mRNA expression levels of B7-H3 and IL-13 decreased, while SP-A and IL-12 increased, in response to QZZKF, QZZKF combined with AZM, and AZM. Statistical differences were detected between QZZKF and AZM, as well as between QZZKF combined with AZM and AZM, and between QZZKF and QZZKF combined with AZM. In conclusion: these results demonstrate that QZZKF combined with AZM exhibited protective effects on airway inflammation and inhibited the progression of MPP better than conventional treatments combined with western medicine.
\end{abstract}

\begin{tabular}{l} 
Article Information \\
\hline Received 06 November 2019 \\
Revised 25 June 2020 \\
Accepted 20 January 2021 \\
Available online 30 July 2021 \\
(early access) \\
Published 20 November 2021 \\
Authors' Contribution \\
X-FW designed the experiments. \\
O-MH drafted the manuscript. Z-JY, \\
C-HN, TZ and Y-FL conducted the \\
experiments.YY helped in processing \\
the medicine. XZ contributed to the \\
statistical analysis. \\
Key words \\
\hline Azithromycin, Lung inflammatory, \\
Mycoplasma pneumoniae, Qing Zhi \\
Zhi Ke formula
\end{tabular}

Article Information

Revised 25 June 2020

(early access)

Published 20 November 202

uthors' Contribution

$\mathrm{X}-\mathrm{FW}$ designed the experiments.

C-HN, TZ and Y-FL conducted the

experiments. YY helped in processin

the medicine. $\mathrm{XZ}$ contributed to the

statistical analysis.

Azithromycin, Lung inflammatory,

Zhi Ke formula

\section{INTRODUCTION}

$M$ coplasma pneumoniae (MP) is a common pathogen that causes atypical pneumonia and bronchitis in children, and its morbidity has gradually increased in recent years. In China, MPP accounts for 1.2\%-34.3\% of pediatric community-acquired pneumonia with an increasing frequency based on age (Zhimin, 2008; Quan and Min, 2007). Although MPP is usually a benign selflimited disease, it may develop into a severe life-threatening pneumonia in rare cases (Ou et al., 2008; Lee et al., 2006; Tamura et al., 2008). Azithromycin (AZM) is usually the first treatment choice for MPP in children at our hospital. In this paper, we evaluated the efficacy of oral prednisolone at a dose of $2 \mathrm{mg} / \mathrm{kg} /$ day (divided into two doses)

\footnotetext{
Corresponding author: 24569573@qq.com 00030-9923/2022/0001-0183 \$ 9.00/0

Copyright 2022 Zoological Society of Pakistan
}

administered with intravenous AZM for five days to children with refractory MPP in a prospective fashion.

Surfactant protein A (SP-A) is a highly oligomeric protein component of pulmonary surfactant that belongs to the collagen domain containing-C type lectin (collectin) superfamily (Julie et al., 2015). Previous studies identified associations of specific SP-A alleles with infant wheezing (Melinda et al., 2007), tuberculosis (Joanna et al., 2000), respiratory distress syndrome (Floros et al., 2001a, b), respiratory syncytial virus infections (EI-Saleeby et al., 2010), and chronic obstructive pulmonary disease (Guo et al., 2000). SP-A plays a crucial role in pneumonia pathogenesis and binds live MP and mycoplasma membrane fractions with high affinity, which were once considered to be closely associated with refractory MPP. The expression of stimulatory and inhibitory B7 molecules seems to play an essential role in modulating immune cell functions through a variety of mechanisms, which is supported by previous findings that suggest that each B7 
molecule has developed its own indispensable niche in the immune system. Another finding reported that B7 homolog 3 protein $(\mathrm{B} 7-\mathrm{H} 3)$ decreased CD4+ T-cell functioning and skewed the CD4+ T-cell immunoresponses (Joseph and Stephen, 2013). Several clinical studies have reported that inflammation factors (IF) are associated with MP in children. These cytokines consist of interleukin (IL)-4, IL5, IL-6, IL-10, IL-13, and IL-17 (Shao et al., 2015; Chen et al., 2016; Yan, 2016; Wang et al., 2016; Medjo et al., 2017; Zhao et al., 2017). Some cytokines are recognized to play a pivotal role in innate defenses against MP, such as IL-12 and IL-13, during the initial stages of infection (Ângela et al., 2018; He et al., 2019).

Qing Zhi Zhi Ke formula (QZZKF) is a preparation developed by pediatricians at Liaoning Hospital (Liaoning University of Traditional Chinese Medicine (TCM), Liaoning, China) that has been shown to have curative effects in response to MPP. QZZKF which consists of white mulberry root bark, fried almonds, purple perilla, cape jasmine, Scutellaria, fritillary, Ophiopogon japonicus, loquat, Platycodon, and Licorice, is frequently used in the treatment of respiratory system diseases, such as cough and pneumonia, in TCM. Increasing evidences have indicated that QZZKF has the potential to relieve inflammatory changes around the lungs and airways in mice infected with MP (Wu et al., 2017, 2018). However, studies on QZZKF remain at the exploratory stage at present and there are still many unclear issues to be clarified and explored. In the present study, the therapeutic effects of QZZKF has been explored on the expression levels of SP-A, sB7-H3, IL-12, and IL-13 in an MMP model.

\section{MATERIALS AND METHODS}

\section{Mice}

Female BALB/c mice (aged 3-5 weeks) were purchased from the Experimental Animal Center of Liaoning University of TCM and housed in a pathogenfree rodent facility. Food and water was made avialbale ad libitum. All experimental animal protocols were approved by the Institutional Animal Care and conducted according to the internationally accepted principles for laboratory animal use and care.

\section{Chemicals and reagents}

Morphoside standard chemical was obtained from Shanghai Yuanye Biotechnology Co., Ltd. (W21M7K15022, Shanghai, China). Standard chemicals including amygdalin, geniposide and baicalin were obtained from Beijing Suolaibao Technology Co., Ltd. (1118A024, 1203A024, 114E021, Beijing,China).AZM was purchased from Pfizer Pharmaceutical Co., Ltd.
(X25459, Beijing, China). Trizol reagent was purchased from Takara Biotechnology (Dalian, China). Anti-sB7-H3 and anti-IL-12 antibodies were purchased from Bioss (AD04085689, AG07202594, Beijing, China). Anti-IL-13 antibody was purchased from Boster (Y-B207C16B, Wuhan, China). Anti-SP-A antibody was purchased from Proteinech (00002470, Wuhan, China).

\section{Preparation of QZZKF extract}

QZZKF components, including white mulberry root bark, fried almonds, purple perilla, cape jasmine, Scutellaria, Fritillary, Ophiopogon japonicus, loquat, platycodon, and licorice, were purchased from the Affiliated Hospital of Liaoning University of TCM (Liaoning, China) and were identified by Prof. Yan Yu of the Affiliated hospital of Liaoning University of TCM. These 10 herbs were mixed in a ratio of $1: 1: 1: 0.8: 1: 0.2: 1: 1: 0.6: 0.3(\mathrm{w} / \mathrm{w})$ respectively. Granules were extracted with eight volumes of distilled water for 60 min using the reflux method. The extraction procedure was repeated three times, and the total extract was filtered. The sieved decoction was evaporated in vacuo with a yield of $16.2 \%$. White mulberry root bark, fried almonds, cape jasmine and scutellaria are the four main herbs of QZZKF. The contents of baicalin, geniposide, morphoside $\mathrm{G}$, and amygdalin in QZZKF extract were 30 $\mathrm{mg} / \mathrm{g}, 7.1 \mathrm{mg} / \mathrm{g}, 0.037 \mathrm{mg} / \mathrm{g}$, and $3.8 \mathrm{mg} / \mathrm{g}$, respectively (based on an HPLC analysis, data not shown).

\section{MP culture}

The MP international standard strain was provided by the virus laboratory in the Affiliated Hospital of Liaoning University of TCM. The main components in the fluid media were bovine brain-heart infusion medium, sterile fetal bovine serum, fresh yeast extract, glucose, penicillin, and phenol red at a $\mathrm{pH}$ of 7.6. Bacteria liquid for testing was diluted from $1 \times 10^{-1}$ to $1 \times 10^{-12}$ using the serial dilution method. After constant temperature incubation at $37^{\circ} \mathrm{C}$ for 14 days, the highest dilution when the red medium changed to yellow was used as the color change unit (CCU). Bacterium concentration was calculated as CCU/ $\mathrm{mL}$.

\section{Establishment of MMP animal model and treatment}

Fifty female BALB/c mice weighing $20 \pm 3 \mathrm{~g}$ were randomly divided into five groups (10 mice/group) as follows: control, model, AZM $(0.01 \mathrm{~g} / \mathrm{kg} /$ day, once daily), QZZKF (10.16 g/ $/ \mathrm{kg} /$ day, divided into two daily doses), and AZM $(0.01 \mathrm{~g} / \mathrm{kg} /$ day, once daily) combined with QZZKF (10.16 g/kg/day, divided into two daily doses). AZM and QZZKF were administered to mice by oral gavage for five days. Mice in the control group were treated with $50 \mu \mathrm{L}$ of normal saline by nasal drip. The model, AZM, QZZKF, 
and AZM combined with QZZKF groups were treated with nasal drops containing $50 \mu \mathrm{L}$ MP for three days.

Mice in the model group were administered a corresponding volume of distilled water. All mice were fed a normal diet and water ad libitum. Body weight was documented every week.

\section{Histopathological evaluation of the lungs}

The upper lobe of the right lung, which was not lavaged, was fixed in $4 \%$ phosphate-buffered paraformaldehyde for $48 \mathrm{~h}$. It was then embedded in paraffin, cut into transverse sections $(5 \mu \mathrm{m})$, and stained with hematoxylin and eosin $(\mathrm{H}$ and E). Morphometric analysis were performed using an optical microscope (Leica DM LB; Leica Microsystems, Wetzlar, Germany).

\section{Immunohistochemistry staining}

Paraffin sections were prepared for immunohistochemical analyses using diaminobenzidine (DAB) purchased from Zhongshan Jinqiao Biotechnology Co. Ltd. (Beijing, China). The subsequent procedure was performed following the manufacturer's instructions (described below). Sections were incubated in $3 \%$ hydrogen peroxide for $10 \mathrm{~min}$ and washed three times (3 min each) with $0.01 \mathrm{mmol} / \mathrm{L}$ PBS (pH 7.4). Antigenic site retrievals were accomplished by the microwave heatmediated method and incubated with $10 \mathrm{mmol} / \mathrm{L}$ citrate buffer ( $\mathrm{pH} 6$ ) for $10 \mathrm{~min}$. Sections were incubated for $2 \mathrm{~h}$ at $37^{\circ} \mathrm{C}$ with the antibody in $0.3 \%$ Triton PBS $(0.01 \mathrm{mmol} / \mathrm{L})$. Then, biotinylated goat anti-rat IgG was added for $20 \mathrm{~min}$ at $37^{\circ} \mathrm{C}$. After rinsing with $0.01 \mathrm{mmol} / \mathrm{L}$ PBS for $6 \mathrm{~min}$, sections were incubated with $\mathrm{DAB}$ for $15 \mathrm{~min}$ at $37^{\circ} \mathrm{C}$, washed with PBS for $10 \mathrm{~min}$, and dyed with hematoxylin for $20 \mathrm{~s}$. Images were analyzed using Image-Pro Plus v6.0 software. For the staining analyses, integrated optical densities (IODs) of positively stained areas in one section at $200 \times$ magnification were determined.

\section{Quantitative real-time PCR analysis}

Total RNA was extracted from frozen right lung tissues using Trizol reagent. A total of $800 \mathrm{ng}$ RNA was reverse transcribed to cDNA in a $20 \mu \mathrm{L}$ reaction system using a Primescript ${ }^{\mathrm{TM}} \mathrm{RT}$ Reagent Kit (A121067A, Takara Biotechnology, Dalian, China). Quantitative realtime (qRT)-PCR was performed using a TB Green ${ }^{\mathrm{TM}}$ Premix ExTaq ${ }^{\mathrm{TM} I I}$ Tli RNaseH Plus kit following the manufacturer's instructions (A171767A, Takara Biotechnology, Dalian, China). The expression of the housekeeping gene, GAPDH, was used as an internal control. RNA levels were determined by Bomaide Bioer Technology Co., Ltd. (Beijing, China). Analyses of qRT-PCR products were performed using Gel-Pro v4.0 software (Sigma-Aldrich Corporation, St. Louis, MO, USA). Sequences of the forward (F) and reverse (R) primers were as follows:

B7-H3, R 5-GACACGGATGCCACCCTACGCTG-3 and R 5-CTGTGATGGTGACTGAGCCGTGAG-3; IL-12, F CACACTGGACCAAAGGGACT-3 and $\mathrm{R}$ 5-TGGTTTGATGATGTCCCTGA-3; SP-A, F 5-GCTCAGCCTTAAGAACATGTGTAAGC-3 and 5-GCCTCATACTCTTCTCGTTGGG-3; IL-13, 5-CTGCCCGTCTTCAGCCTAGCCG and 3-CGAGGCCCCAGGACCCCAG. Relative gene expression was calculated using the $2^{-\Delta \Delta \mathrm{Ct}}$ method. Data were normalized to GAPDH gene expression levels.

\section{Statistical analysis}

Data were analyzed using SPSS v10.01 software (SPSS Inc., Chicago, IL, USA). Quantitative data were expressed as the mean \pm standard deviation (SD). A Student's t-test or one-way analysis of variance (ANOVA) followed by Bonferroni test was used to analyze significant differences between the means. A $p$-value $<0.05$ was considered statistically significant.

\section{RESULTS}

\section{Lung tissue pathology}

All lung tissues appeared normal in the control group. There were no obvious pathological changes in the alveoli or alveolar walls and no obvious infiltration of inflammatory cells. The lung tissues of the model group overall appeared abnormal, characterized by atrophy or the disappearance of alveoli and lung parenchyma, as well as infiltration of neutrophilic and lymphocytic. The lung tissues of the AZM group overall appeared abnormal with atrophy or the disappearance of alveoli, and infiltration of a small number of inflammatory cells. The lung tissues of the QZZKF group, showed initial neutrophilic infiltration of the alveoli, followed by lymphocytic infiltrates thereafter. The lung tissues of the AZM combined with QZZKF group appeared mildly abnormal with inflammatory cell infiltration and visible endobronchial inflammatory exudate (Fig. 1).

Expression of $S P-A, B 7-H 3, I L-12$, and $I L-13$ protein determined by immunohistochemistry

The expression levels of SP-A, B7-H3, IL-12, and IL13 proteins in the lung tissues of mice were determined by immunohistochemistry (Fig. 2, Table I). Inflammatory cytokines play crucial roles in inflammatory responses and airway hypersensitivity. The levels of B7-H3 and IL-13 significantly increased in the model group when compared to the control group. QZZKF and AZM significantly 
decreased the expression levels of these cytokines. QZZKF combined with AZM decreased the expression of these cytokines when compared to the AZM and QZZKF groups. The protein expression of SP-A and IL-12 significantly decreased in the model group when compared to the control group. The level of SP-A in QZZKF combined with AZM significantly increased compared to neither the AZM group nor the QZZKF group. The level of IL-12 in QZZKF combined with AZM significantly increased when compared to the AZM group but was not significantly different when compared to the QZZKF group.

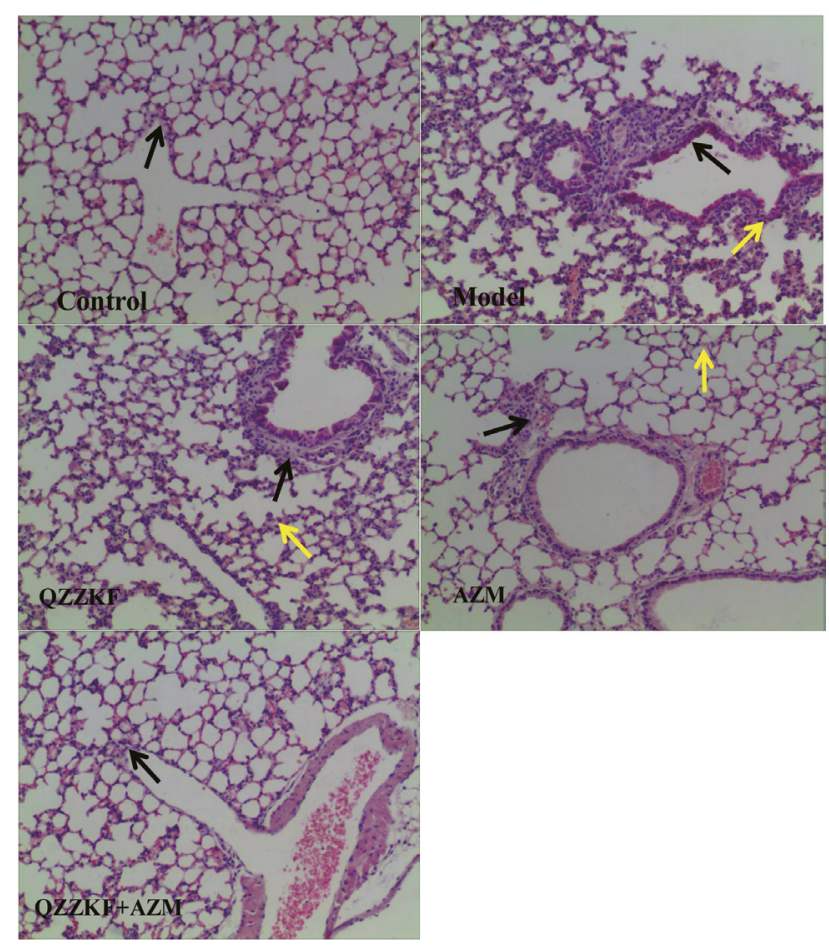

Fig. 1. Effects of QZZKF on morphological changes in the lung tissues of mice. The inferior lobe of the right lung was harvested after the final exposure after five days of treatment; sections were stained with hematoxylin and eosin $(200 \times)$. Black arrow, infiltration of inflammatory cells. Yellow arrow, atelectasis and alveolar collapse.

\section{SP-A, B7-H3, IL-12, and IL-13 mRNA expression}

A quantitative diagnostic kit was used to investigate the therapeutic effects of QZZKF and AZM (Fig. 3, Table II). Results revealed that the levels of B7-H3 and IL-13 mRNA in the lung tissues of the model group were considerably higher compared to the other groups. AZM or QZZKF treatment reduced the expression levels of B7-H3 and IL-13 when compared to the model group. QZZKF combined with AZM further reduced the levels of B7-H3 and IL-13 when compared to the AZM group, suggesting that QZZKF combined with AZM had better therapeutic effects than AZM. The gene expression levels of SP-A and IL-12 significantly decreased in the model group when compared to the control group. The levels of SP-A in QZZKF combined with AZM significantly higher than that was in QZZKF and AZM group. The levels of IL-12 in QZZKF combined with AZM significantly increased when compared to the AZM group.

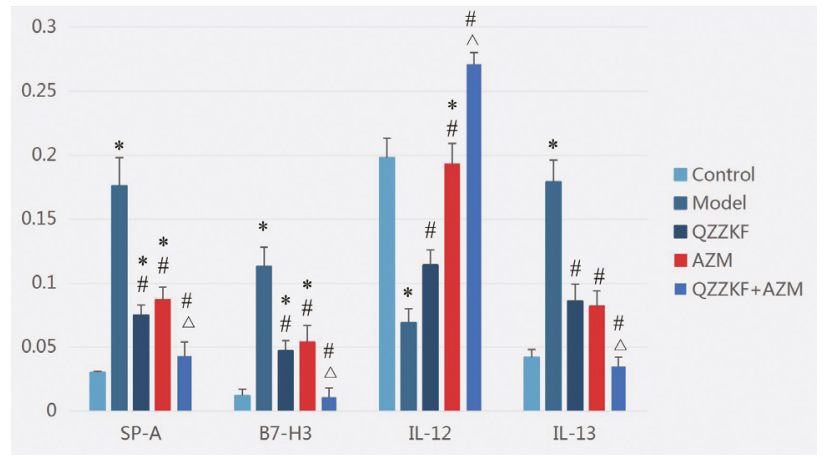

Fig. 2. QZZKF regulated SP-A, B7-H3, IL-12, and IL-13 expression levels in the lung tissues of mice. Data are presented as the mean $\pm \mathrm{SD}(\mathrm{n}=8-10) .{ }^{*} p<0.05$ compared to the control group; ${ }^{\#} p<0.05$ compared to the model group; and ${ }^{\otimes} p<0.05$ compared to the AZM group.

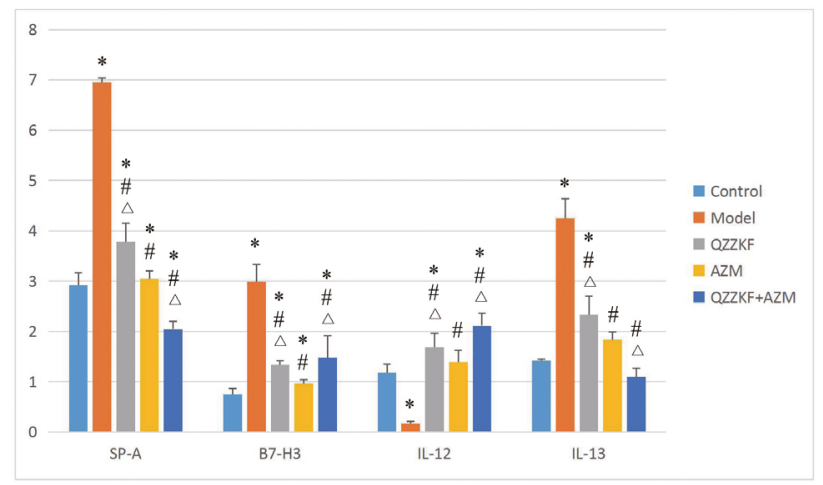

Fig. 3. Gene expression levels of SP-A, B7-H3, IL-12, and IL-13 in the lung tissues of mice. Data are presented as the mean \pm SD $(\mathrm{n}=8-10) .{ }^{*} p<0.05$ compared to the control group; ${ }^{*} p<0.05$ compared to the model group; and ${ }^{\otimes} p<0.05$ compared to the AZM group.

\section{DISCUSSION}

MP infections cause tracheobronchitis and "walking" pneumonia and are linked to asthma and other reactive airway diseases. Some researchers have hypothesized that MPP sensitization and challenges induce collagen deposition in the tracheal and bronchial submucosa of $\mathrm{BALB} / \mathrm{c}$ mice, resulting in airway reconstruction and 
subsequent severe bronchial hyper-responsiveness and asthmatic symptoms (Chu et al., 2005). As part of the infectious process, the community acquired respiratory distress syndrome toxins bind to SP-A and annexin A2 on airway epithelial cells and are internalized, leading to a range of pathogenetic events (Becker et al., 2015). SP-A plays crucial role in pneumonia pathogenesis and leads to the differential binding of MP membranes and regulation of host responses. Ledford et al. (2012) found that SP-A could suppress the eosinophil-mediated killing of MP in allergic lungs. Although mycoplasmas lack the LPSs found in gram-negative bacteria, they express several cell surface ligands capable of interacting with SP-A. SP-A binding to MP inhibits the growth of organisms (Piboonpocanun et al., 2005). As reported, SP-A is expressed in alveolar type II cells, Clara cells, and submucosal glands of the respiratory airways and has been detected in epithelial cells lining extrapulmonary sites (Balis et al., 1985; Khubchandani and Snyder, 2001). Since SP-A stimulates phagocytosis by binding to alveolar macrophages, it is considered an important contributor to innate lung immunity. In this study, SP-A levels increased in response to MP infection and QZZKF effectively decreased the levels of SP-A, which was better than AZM. However, QZZKF combined with AZM exhibited the best therapeutic effects, better than AZM or QZZKF, suggesting that QZZKF combined with AZM may be useful as an anti-MP agent.

$\mathrm{B} 7-\mathrm{H} 3$ is an immune checkpoint molecule that belongs to the B7-CD28 family and was discovered in 2001 (Chapoval et al., 2001). This molecule has been associated with costimulatory and coinhibitory functions in regulating T-cell responses. Prasad reported that in mouse models of airway inflammation, B7-H3 downregulated Th1, but not Th2, responses, and B7-H3 gene knock-out mice developed severe airway diseases when compared to the wild type (Prasad et al., 2004). B7-H3 substantially augmented pro-inflammatory cytokine production in the development of pneumococcal meningitis in a murine model (Chen et al., 2012). Children with MPP had significantly higher levels of B7-H3 compared to the controls, and children with MPP combined with pleural effusion exhibited significantly higher levels of B7-H3 compared to those without effusion. The level of B7-H3 was positively correlated with the duration of fever in the clinical parameters of children with MPP (Li et al., 2019). Results of the present study indicated that MP infection increased the expression levels of B7-H3 (Figs. 2 and 3). The QZZKF group reduced the expression of B7-H3 when compared to the AZM group, suggesting that QZZKF combined with AZM exhibited better therapeutic effects than AZM.

Table I. Effects of QZZKF and AZM on the lung tissues of MPP mice.

\begin{tabular}{llllll}
\hline Groups & $\mathbf{n}$ & SP-A & B7-H3 & IL-12 & IL-13 \\
\hline Control & 10 & $0.030 \pm 0.001$ & $0.012 \pm 0.005$ & $0.198 \pm 0.015$ & $0.042 \pm 0.006$ \\
Model & 8 & $0.011 \pm 0.022^{*}$ & $0.113 \pm 0.015^{*}$ & $0.069 \pm 0.011^{*}$ & $0.179 \pm 0.017^{*}$ \\
QZZKF & 10 & $0.075 \pm 0.008^{* \#}$ & $0.047 \pm 0.008^{* \#}$ & $0.114 \pm 0.012^{\#}$ & $0.086 \pm 0.013^{\#}$ \\
AZM & 9 & $0.087 \pm 0.010^{* \#}$ & $0.054 \pm 0.013^{* \#}$ & $0.193 \pm 0.016^{* \#}$ & $0.082 \pm 0.012^{\#}$ \\
QZZKF+AZM & 9 & $0.043 \pm 0.011^{\# \Delta S}$ & $0.011 \pm 0.007^{\# S \Delta}$ & $0.271 \pm 0.009^{\# \Delta}$ & $0.035 \pm 0.007^{\# \Delta S}$ \\
\hline
\end{tabular}

Data are presented as the mean $\pm \mathrm{SD}(\mathrm{n}=8-10) .{ }^{*} p<0.05$ compared to the control group; ${ }^{*} p<0.05$ compared to the model group; ${ }^{\otimes} p<0.05$ compared to the AZM group; and ${ }^{\mathrm{s}} p<0.05$ compared to the QZZKF group.

Table II. Gene expression levels of SP-A, B7-H3, IL-12, and IL-13 in MPP mice of different groups.

\begin{tabular}{llllll}
\hline Groups & $\mathbf{n}$ & SP-A & B7-H3 & IL-12 & IL-13 \\
\hline Control & 10 & $2.921 \pm 0.241$ & $0.755 \pm 0.110$ & $1.183 \pm 0.164$ & $1.418 \pm 0.031$ \\
Model & 9 & $1.250 \pm 0.087^{*}$ & $2.989 \pm 0.341^{*}$ & $0.167 \pm 0.042^{*}$ & $4.251 \pm 0.386^{*}$ \\
QZZKF & 9 & $3.785 \pm 0.363^{* * \Delta}$ & $1.333 \pm 0.078^{* \# \Delta}$ & $1.680 \pm 0.282^{* \# \Delta}$ & $2.331 \pm 0.367^{* \# \Delta}$ \\
AZM & 10 & $3.041 \pm 0.163^{* \#}$ & $0.960 \pm 0.074^{* \#}$ & $1.387 \pm 0.240^{\#}$ & $1.838 \pm 0.151^{\#}$ \\
QZZKF+AZM & 10 & $2.143 \pm 0.159^{* \# \Delta S}$ & $1.482 \pm 0.429^{* \# \Delta S}$ & $2.116 \pm 0.244^{* \# \Delta}$ & $1.096 \pm 0.169^{\# \Delta S}$ \\
\hline
\end{tabular}

Data are presented as the mean $\pm \mathrm{SD}(\mathrm{n}=9-10) .{ }^{*} p<0.05$ compared to the control group; ${ }^{*} p<0.05$ compared to the model group; ${ }^{4} p<0.05$ compared to the AZM group; and ${ }^{\mathrm{s}} p<0.05$ compared to the QZZKF group. 
A wide range of cytokines and chemokines were generated in the respiratory tracts infected by MP (Hardy et al., 2019; Kurai et al., 2013; Narita and Tanaka, 2012). B7-H3 plays a vital role in T-cell differentiation, such as Th1 cells (Chapoval et al., 2001). Thus, it is presumed that B7-H3 may be associated with IL-12 and IL-13 in patients with MPP. IL-12 is one of the most important Th1 cytokines that connects the innate and adaptive immune systems, and its most distinctive function is regulating the balance of Thl/Th2. When IL-12 is insufficient, Th1 responses are low and Th2 responses are enhanced. Meanwhile, IL-12 has an inhibitory effect on the production of Th 2 cytokines, such as IL-13 and IL-4, which inhibit Th2 responses and reduce airway inflammation. IL-13 is a pleiotropic cytokine produced in large quantities by stimulated Th2 cells. IL-13 has many overlapping biological activities pertinent to the development of allergic responses in asthmatic airways. It is highly expressed in airways of subjects with atopic and non-atopic asthma and is possibly involved in the airway remodeling response and development of airway hyperresponsiveness (EI-Bassam et al., 2005). As previously reported, many constituents of QZZKF, specifically mulberry skin, fried almonds, and Scutellaria, attenuate the infiltration of inflammatory cells and decrease the concentration of cytokines (Jiang et al., 2017; Kan and Jiang, 2019). In the present study, QZZKF effectively decreased the levels of IL-13 and increased the levels of IL-12, which contributed to the alleviation of inflammatory responses in the lung tissues of experimental mice on both the protein and gene levels. Mice in the QZZKF combined with AZM group exhibited greatly reduced IL-12 expression compared to the QZZKF and AZM group on the gene level. Meanwhile, there were no significant differences detected between the IL-12 protein expression levels of the QZZKF combined with AZM and QZZKF groups. These results suggest that QZZKF exhibited better therapeutic effects than AZM.

In conclusion, the findings of this study suggest that QZZKF exhibited a significant protective effect against MP infection by ameliorating airway and lung inflammation, which may be related to the downregulation of the SPA, B7-H3, and IL-13 signaling pathways and promotion of the expression of IL-12, thereby providing promising insights into anti-MPP therapy.

\section{ACKNOWLEDGMENTS}

This work was supported by the National Natural Science Foundation of China Project (No. 8177150255) and by Liaoning province education department funds (No. 11020138170112). We would like to give our sincerest appreciation to the reviewers of this manuscript for their helpful comments. We thank LetPub (www.letpub.com) for its linguistic assistance during the preparation of this manuscript.

Statement of conflict of interest

The authors have declared no conflict of interest.

\section{REFERENCES}

Ângela, G.V., Jorge, C., Daniela, A., Maria-Regina, A.C., Aldina, B. and Cristiana, M.N., 2018. Systemic cytokines and chemokines on admission of children hospitalized with community-acquired pneumonia. Cytokine, 107: 1-8. https://doi. org/10.1016/j.cyto.2017.11.005

Balis, J.U., Paterson, J.F., Paciga, J.E., Haller, E.M. and Shelley, S.A., 1985. Distribution and subcellular localization of surfactant-associated glycoproteins in human lung. Lab. Investig., 52: 657-669.

Becker, A., Kannan, T.R., Taylor, A.B., Pakhomova, O.N., Zhang, Y., Somarajan, S.R., Galaleldeen, A., Holloway, S.P., Baseman, J.B. and Hart, P.J., 2015. Structure of CARDS toxin, a unique ADP-ribosylating and vacuolating cytotoxin from Mycoplasma pneumoniae. Proc. natl. Acad. Sci., 112: 5165-5170. https://doi.org/10.1073/ pnas. 1420308112

Chapoval, A.I., Ni, J., Lau, J.S., Wilcox, R.A., Flies, D.B., Liu, D., Dong, H., Sica, G.L., Zhu, G., Tamada, K. and Chen, L., 2001. B7-H3: A costimulatory molecule for $\mathrm{T}$ cell activation and IFN-gamma production. Nat. Immunol., 2: 269274. https://doi.org/10.1038/85339

Chen, X., Quinn, E.M., Ni, H., Wang, J., Blankson, S., Redmond, H.P., Wang, J.H. and Feng, X., 2012. B7H3 participates in the development of experimental pneumococcal meningitis by augmentation of the inflammatory response via a TLR2-dependent mechanism. J. Immunol., 189: 347-355. https://doi. org/10.4049/jimmunol.1103715

Chen, Z., Shao, X., Dou, X., Zhang, X., Wang, Y., Zhu, C., Hao, C., Fan, M., Ji, W. and Yan, Y., 2016. Role of the Mycoplasma pneumoniael interleukin-8/ neutrophil axis in the pathogenesis of pneumonia. PLoS One, 11: e0146377. https://doi.org/10.1371/ journal.pone. 0146377

Chu, H.W., Rino, J.G., Wexler, R.B., Campbell, K., Harbeck, R.J. and Martin, R.J., 2005. Mycoplasma pneumoniae infection increases airway collagen deposition in a murine model of allergic airway inflammation. Am. J. Physiol. Lung Cell Mol. Physiol., 289: L125-L133. https://doi.org/10.1152/ 
ajplung.00167.2004

EI-Bassam, S., Pinsonneault, S., Kornfeld, H., Ren, F.C., Menezes, J. and Laberge, S., 2005. Interleukin-16 inhibits interleukin-13 production by allergen- stimulated blood mononuclear cells. Immunology, 117: 89-96. https://doi.org/10.1111/ j.1365-2567.2005.02269.x

EI-Saleeby, C.M., Li, R., Somes, G.W., Dahmer, M.K., Quasney, W. and DeVincenzo, J.P., 2010. Surfactant protein A2 polymorphisms and disease severity in a respiratory syncytial virus-infected population. $J$. Pediatr., 156: 409-414. https://doi.org/10.1016/j. jpeds.2009.09.043

Floros, J., Fan, R., Diangelo, S., Guo, X., Wert, J. and Luo, J., 2001a. Surfactant protein (SP) B associations and interactions with SP-A in white and black subjects with respiratory distress syndrome. Pediatr. Int., 43: 567-576. https://doi. org/10.1046/j.1442-200X.2001.01474.x

Floros, J., Fan, R., Matthews, A., DiAngelo, S., Luo, J., Nielsen, H., Dunn, M., Gewolb, I.H., Koppe, J., van Sonderen, L., Farri-Kostopoulos, L., Tzaki, M., Rämet, M. and Merrill, J., 2001b. Family-based transmission disequilibrium test (TDT) and casecontrol association studies reveal surfactant protein A (SP-A) susceptibility alleles for respiratory distress syndrome (RDS) and possible race differences. Clin. Genet., 60: 178-187. https://doi. org/10.1034/j.1399-0004.2001.600303.x

Guo, X., Lin, H.M., Lin, Z., Montaño, M., Sansores, R., Wang, G., DiAngelo, S., Pardo, A., Selman, M. and Floros, J., 2000. Polymorphisms of surfactant protein gene A, B, D, and of SP-B-linked microsatellite markers in COPD of a Mexican population. Chest, 117: 249S-250S. https://doi. org/10.1378/chest.117.5_suppl_1.249S-a

Hardy, R.D., Jafri, H.S., Olsen, K., Wordemann, M., Hatfield, J., Rogers, B.B., Patel, P., Duffy, L., Cassell, G., McCracken, G.H. and Ramilo, O., 2001. Elevated cytokine and chemokine levels and prolonged pulmonary airflow resistance in a murine Mycoplasma pneumoniae pneumonia model: A microbiologic, histologic, immunologic, and respiratory plethysmographic profile. Infect. Immun., 69: 3869-3876. https://doi.org/10.1128/ IAI.69.6.3869-3876.2001

He, J.E., Qu, H. and Gao, C.Y., 2019. Association between inflammation factors and Mycoplasma pneumoniae in children. Medicine, 98: 15. https:// doi.org/10.1097/MD.0000000000015118

Jiang, M.C., Dai, Q.G., Xu, S. and Wang, S.C., 2017. Study on medication rules in treating cough caused by Mycoplasma pneumoniae of WANG Shouchuan. China J. Trad. Chinese Med. Pharm., 32: 4893-4897.

Joanna, F., Hung-Mo, L., Andrea, G., Miguel, A.S., Xiao, X.G., Susan, D.A., Martha, M., Jun, M.L., Annie, P. and Moises, S., 2000. Surfactant protein genetic marker alleles identify a subgroup of tuberculosis in a Mexican population. J. Infect. Dis., 182: 14731478. https://doi.org/10.1086/315866

Joseph RP and Stephen DM, 2013. Targeting the B7 family of co-stimulatory molecules: Successes and challenges. Biol. Drugs, 27: 1-13. https://doi. org/10.1007/s40259-012-0001-6

Julie, G.L., Dennis, R.V., Kenneth, J.A., Ying, W., Vinayak, S.N., Simone, D., Pitachaimani, K., Sasipa, T., Bernard, M.F., Monica, K. and John, W.H., 2015. Genetic variation in surfactant protein-A2 (SP-A2) leads to differential binding to Mycoplasma pneumoniae membranes and regulation of host response. J. Immunol., 194: 6123-6132.

Kan, Q. and Jiang, Z.Y., 2019. Study on mechanism of inhibiting Mycoplasma pneumoniae by traditional Chinese medicine. Chinese Arch. Trad. Chinese Med., 37: 658-660.

Khubchandani, K.R. and Snyder, J.M., 2001. Surfactant protein A (SP-A): The alveolus and beyond. FASEB J., 15: 59-69. https://doi.org/10.1096/fj.00-0318rev

Kurai, D., Nakagaki, K., Wada, H., Saraya, T., Kamiya, S., Fujioka, Y., Nakata, K., Takizawa, H. and Goto, H., 2013. Mycoplasma pneumoniae extract induces an IL-17-associated inflammatory reaction in murine lung: Implication for mycoplasmal pneumoniae. Inflammation, 36: 285-293. https:// doi.org/10.1007/s10753-012-9545-3

Ledford, J.G., Mukherjee, S., Kislan, M.M., Nugent, J.L., Hollingsworth, J.W. and Wright, J.R., 2012. Surfactant protein-A suppresses eosinophilmediated killing of Mycoplasma pneumoniae in allergic lungs. PLoS One, 7: e32436. https://doi. org/10.1371/journal.pone.0032436

Lee, K.Y., Lee, H.S., Hong, J.H., Lee, M.H., Lee, J.S., Burgner, D. and Lee, B.C., 2006. Role of prednisolone treatment in severe Mycoplasma pneumoniae pneumonia in children. Pediatr. Pulmonol., 41: 263-268. https://doi.org/10.1002/ ppul.20374

Li, Q.L., Wu, Y.Y., Sun, H.M., Gu, W.J., Zhang, X.X., Wang, M.J., Yan, Y.D., Hao, C.L., Wei, J. and Chen, Z.R., 2019. The role of miR-29c/B7-H3/Th17 axis in children with Mycoplasma pneumoniae pneumonia. Ital. J. Pediatr., 45: 61. https://doi. 
org/10.1186/s13052-019-0655-5

Medjo, B., Atanaskovic-Markovic, M., Nikolic, D., Radic, S., Lazarevic, I., Cirkovic, I. and Djukic, S., 2017. Increased serum interleukin-10 but not interleukin-4 level in children with Mycoplasma pneumoniae pneumonia. J. Trop. Pediatr., 63: 294 300.

Melinda, M.P., Janneane, F.G., Yong, Z., Elizabeth, W.T., Kathleen, D.B., Theodore, R.H., Michael, B.B. and Brian, P.L., 2007. Respiratory symptoms among infants at risk for asthma: Association with surfactant protein A haplotypes. BMC Med. Genet., 8: 15 . https://doi.org/10.1186/1471-2350-8-15

Narita, M. and Tanaka, H., 2012. Late increase of interleukin-18 levels in blood during Mycoplasma pneumoniae pneumonia. Cytokine, 59: 18-19. https://doi.org/10.1016/j.cyto.2012.04.007

Ou, Z.Y., Zhou, R., Wang, F.H., Lu, J.P., Xia, J.Q., Xia, H.M., Zhang, J.T., Gong, S.T., Deng, L. and Wu, Z.H., 2008. Retrospective analysis of Mycoplasma pneumoniae infection in pediatric fatal pneumonia in Guangzhou, South China. Clin. Pediatr. (Phila), 47: 791-796. https://doi. org/10.1177/0009922808318339

Piboonpocanun, S., Chiba, H., Mitsuzawa, H., Martin, W., Murphy, R.C., Harbeck, R.J. and Voelker, D.R., 2005. Surfactant protein A binds Mycoplasma pneumoniae with high affifinity and attenuates its growth by recognition of disaturated phosphatidylglycerols. J. biol. Chem., 280: 9-17. https://doi.org/10.1074/jbc.M411570200

Prasad, D.V., Nguyen, T., Li, Z., Yang, Y., Duong, J., Wang, Y. and Dong, C., 2004. Murine B7-H3 is a negative regulator of $\mathrm{T}$ cells. J. Immunol., 173: 2500-2506. https://doi.org/10.4049/ jimmunol.173.4.2500

Quan, L. and Min, L., 2007. Epidemiology of Mycoplasma pneumoniae infection. J. appl. clin. Pediatr., 22: 241-243.

Shao, L., Cong, Z., Li, X., Zou, H., Cao, L. and Guo, Y., 2015. Changes in levels of IL-9, IL-17, IFN- g,dendritic cell numbers and TLR expression in peripheral blood in asthmatic children with Mycoplasma pneumoniae infection. Int. J. clin. exp. Pathol., 8: 5263-5272.

Tamura, A., Matsubara, K., Tanaka, T., Nigami, H., Yura, K. and Fukaya, T., 2008. Effects of methylprednisolone pulse therapy for refractory Mycoplasma pneumoniae pneumonia in children. J. Infect., 57: 223-228. https://doi.org/10.1016/j. jinf.2008.06.012

Wang, Z.H., Li, X.M., Wang, Y.S. and Guo, Z.Y., 2016. Changes in the levels of interleukin-17 between atopic and non-atopic children with Mycoplasma pneumoniae pneumonia. Inflammation, 39: 18711875. https://doi.org/10.1007/s10753-016-0422-3

Wu, Z.Q., Jia, X.R., Min, N., Yue, Z. and Wang, X.F., 2017. Zhang congrong. Influence of Qingzao Jiufei decoction and its decomposable agent on TLR-2/ NF-KB singal pathway in MP infected mice. Chin. Pediatr. Integr. Tradit. West Med., 9: 466-471.

Wu, Z.Q., Min, N., Yue, Z.J., Yang, L., Wang, X.F. and Yang, H., 2018. Effect of Qingzao Jiufei decoction and its decomposing agent on lung inflammation related factors in mice infected with Mycoplasma pneumoniae. Acta Labor. Anim. Sci. Sin., 26:120112.

Yan, T., 2016. Role of anti-inflammatory cytokines in pathogenesis of pediatric Mycoplasma pneumoniae pneumonia. J. Biol. Regul. Homeost. Agents, 30: $541-545$.

Zhao, J., Zhang, W., Shen, L., Yang, X., Liu, Y. and Gai, Z., 2017. Association of the ACE, GSTM1, IL-6, NOS3, and CYP1A1 polymorphisms with susceptibility of Mycoplasma pneumoniae pneumonia in Chinese children. Medicine (Baltimore), 96: e6642. https://doi.org/10.1097/ MD.0000000000006642

Zhimin, C., 2008. Progress in the diagnosis and treatment of childhood Mycoplasma pneumoniae infections. J. clin. Pediatr., 26: 562-565. 